\title{
O PAPEL DA INFORMAÇÃO PARA O SUCESSO DE INICIATIVAS AMBIENTALMENTE AMIGÁVEIS: UM ESTUDO COMPARATIVO ENTRE PRODUTO ECO E CONVENCIONAL
}

Cristina Ely

Fernando Batista Bruno

Universidade Federal do Rio Grande do Sul

fernando.bruno@ufrgs.br

Jocelise Jacques de Jacques

Universidade Federal do Rio Grande do Sul

jocelise.jacques@ufrgs.br

Régio Pierre da Silva

Universidade Federal do Rio Grande do Sul

régio@ufrgs.br

Resumo: A grande variedade de produtos "eco" ou "verdes" disponível no mercado atualmente faz surgir questionamentos sobre a natureza destes produtos: se são realmente ambientalmente amigáveis. Para elucidar dúvidas sobre a diferença entre produtos convencionais e ditos "eco" as informações disponibilizadas ao consumidor são fundamentais, porque também podem ser fator importante para influenciar a preferência ou mesmo a aceitação destes produtos. Neste trabalho tem-se por objetivo demonstrar uma análise comparativa realizada sob a ótica ambiental, entre um produto convencional e outro dito eco, da mesma marca, considerando os critérios de (i) processo de fabricação, e (ii) responsabilidade social, tendo como pano de fundo a investigação da legislação que define algumas características observadas nas duas versões. O objeto de estudo escolhido é filtro coador de papel para preparo de café, utilizou-se as informações fornecidas pela empresa aos seus consumidores e a partir delas traçou-se a diferença entre os produtos. Junto à análise das características ambientais, considera-se também a aceitação do produto eco, que desde 2015 foi retirado do mercado.

Palavras-chave: Desenvolvimento sustentável de produto, métricas de sustentabilidade.

Abstract: The wide range of "eco" or "green" products available today raises some questions about the nature of these products. One of these questions is if they really are environmentally friendly. All information available for the costumers is essential to make clear the difference between conventional and "eco" products and can also be an important factor influencing the preference or acceptance of such products. The aim 
of this paper is to present a comparative analysis performed between a conventional and an "eco" product of the same brand, from the environmental point of view. The criteria considered are (i) manufacturing process, and (ii) the social responsibility, taking into account a background research on the legislation that defines some characteristics observed on both products. The object of study is a paper filter for coffee brewing, and we used the information supplied by the company to its customers to outline the difference between both products. Besides the analysis of the environmental characteristics, we also considered is the acceptance of the eco product (whose production was closed in 2015) among consumers.

Keywords: Sustainable product development, Sustainability metrics.

\section{INTRODUÇÃO}

O apelo dos produtos ditos "verdes" ou "ecos" tem crescido nos últimos anos em todos os setores, e no setor alimentício de forma mais acentuada pela relação direta com a saúde pessoal, que por razões instintivas têm prioridade no nosso processo de tomada de decisão. Mesmo as pessoas que não atentam aos problemas ambientais, mesmo por desconhecimento, demonstram preocupação com aquilo que ingerem e que terá impacto em sua própria existência. Neste cenário, o mercado de produtos orgânicos ou que contemplam características ambientalmente amigáveis tem apresentado crescimento significativo: em 2015 o mercado brasileiro de produtos orgânicos teve um aumento de $35 \%$ em valor, com previsão de aumento de $30 \%$ em 2016 (ORGANICS BRASIL, 2016).

A legislação e fiscalização da produção destes itens deve assegurar sua procedência e pode-se afirmar que o interesse sobre as informações relacionadas atinge cada vez mais consumidores. Estes estão interessados em conhecer a procedência daquilo que ingerem e quais os benefícios para a saúde do indivíduo e do planeta que tais produtos fornecem. No entanto, mesmo com tantas possibilidades de canais de divulgação, nem sempre as informações estão disponíveis como deveriam, no caso de produtos com algum diferencial em seu processo de produção. Uma das discussões levantadas neste artigo tem como cerne o fato de que além dos benefícios reais, o conhecimento sobre estes benefícios deve ser disponibilizado aos consumidores de forma clara e assertiva.

Este é um processo em que as empresas não têm apenas o papel de ofertar algo que o consumidor precise ou deseje, mas também tem a possibilidade e a responsabilidade de educar no sentido de mostrar como uma alteração no processo produtivo pode trazer benefícios ambientais. Questionamos porque esta tarefa não é contemplada de forma mais abrangente por parte das organizações. Para isto utilizamos o exemplo do filtro de café da fabricante líder mundial, que lançou no mercado em 2002, um filtro dito eco o qual teve a produção encerrada em 2015, mantendo a hegemonia do produto convencional. 0 estudo mostra a diferença entre os dois produtos para identificar o benefício ambiental da versão Eco, e a reflexão sobre como melhoramento foi ou não divulgado ao público. Destacando-se inicialmente o tamanho do mercado deste produto, o que evidencia a variedade dos consumidores atingidos e o potencial de atuação em conscientização ambiental que a 
versão eco deteve no período em que foi ofertada.

\section{O MERCADO DE CAFÉ NO BRASIL}

Conforme informação da Associação Brasileira da Indústria de Café (ABIC, 2016), o consumo de café torrado e moído no período de novembro de 2014 a outubro de 2015 foi de 4,90 kg / habitante (equivalente a 81 litros / habitante), indicando um pequeno aumento em relação ao período anterior (4,89 kg / habitante), mas ainda inferior ao índice alcançado em 2012, quando o consumo atingiu 4,98 kg / habitante, o maior já registrado no Brasil (Gráfico 1). 0 valor médio apresentou uma elevação de 16,1\% no ano de 2015, variando de $R \$ 13,93$ / kg em janeiro para $R \$ 16,17$ / kg em dezembro.

Gráfico 1: Evolução do consumo de café torrado e moído no Brasil (kg / habitante)

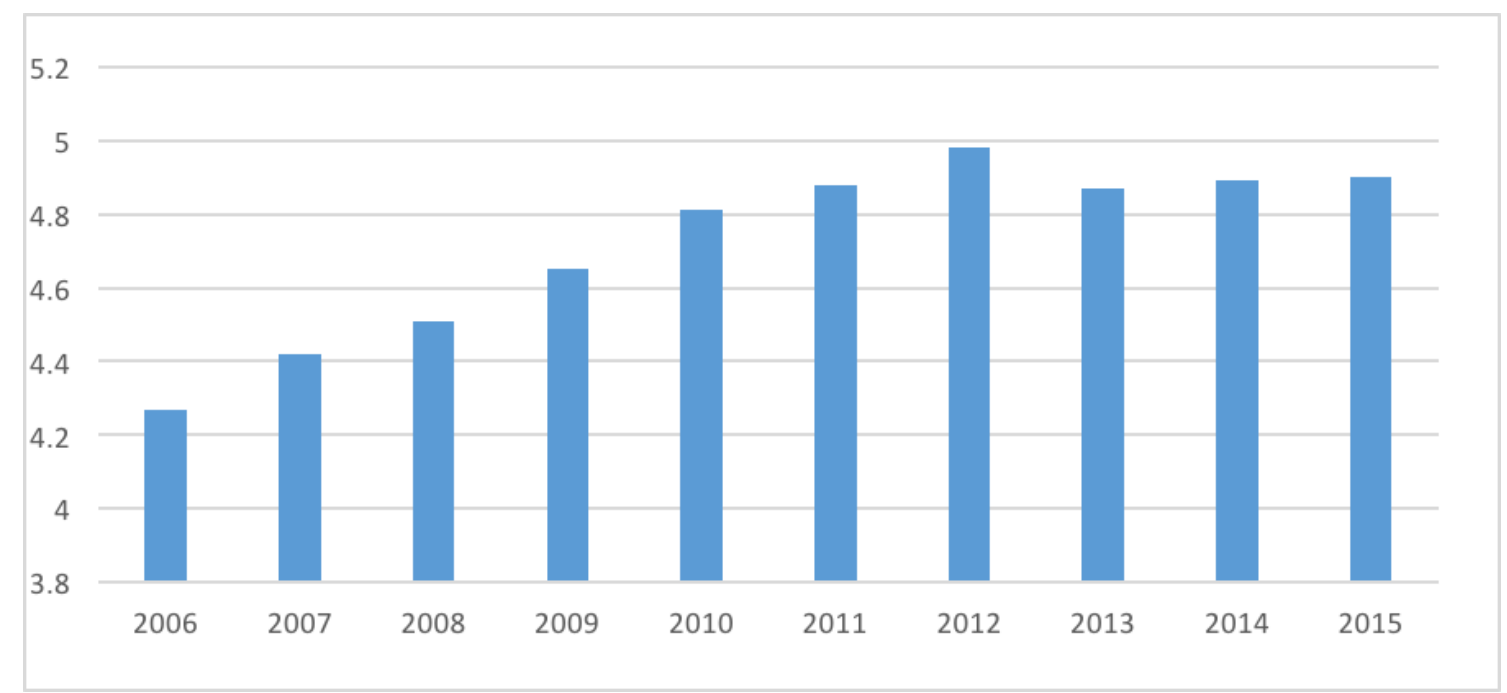

Fonte: ABIC (2016).

A ABIC (2016) apresenta, ainda, algumas tendências verificadas nos indicadores de mercado no período de 2016:

- Aumento acentuado do consumo de café em monodoses (cápsulas, sachês e expressos) - $O$ mercado de cápsulas alcançou o valor de $\mathrm{R} \$ 1,4$ bilhão, com estimativa de alcançar R\$ 2,96 bilhões em 2019.

- Manutenção do interesse do consumidor por cafés certificados pelo PQC (Programa de Qualidade do Café da ABIC) e sustentáveis;

- Crescimento da demanda por cafés gourmet;

No mercado de coadores de papel para café, a empresa líder detinha, em 2012, uma fatia de $62 \%$, incluindo além de sua marca principal outras duas marcas. Os coadores da marca são produzidos em seu parque fabril de Guaíba (RS) (FERREIRA, 2013).

\section{A ORIGEM DO FILTRO DE CAFÉ}

Sobre o histórico do produto sabe-se que o coador de papel foi desenvolvido e patenteado pela dona-de-casa Melitta Bentz (1873 - 1950) em Dresden - Alemanha. Na 
busca por uma bebida que não fosse extremamente amarga e, ao mesmo tempo não deixasse resíduos no fundo da xícara, Melitta Bentz realizou uma série de experimentos utilizando diversos materiais. O melhor resultado foi obtido por meio da aplicação de uma camada de papel mata-borrão no fundo de um recipiente metálico perfurado (SANTOS; LIMA, 2007).

O pó de café era, então, depositado sobre a camada de papel e água fervente despejada sobre ele. Desta forma, a infusão era preparada e filtrada ao mesmo tempo (SANTOS; LIMA, 2007).

A patente do "Filtro de café com fundo abaulado e perfurado forrado com papel filtro" ("Filtrierpapier arbeitenden Kaffeefilter mit auf der Unterseite gewölbtem Boden sowie mit schräg gerichteten Durchflusslöchern") (Figura 1) foi obtida por Melitta Bentz em junho de 1908 (BMAS, 2014). Em dezembro do mesmo ano foi fundada a empresa Melitta Bentz Company e, em 1909, durante uma feira em Leipzig, foram comercializados aproximadamente 1200 destes coadores de café (STANLEY, 1995). A mesma empresa patenteou também os filtros em forma de saco (o formato atual do coador de café) em 1937 e a embalagem de café a vácuo em 1962 (SANTOS; LIMA, 2007).

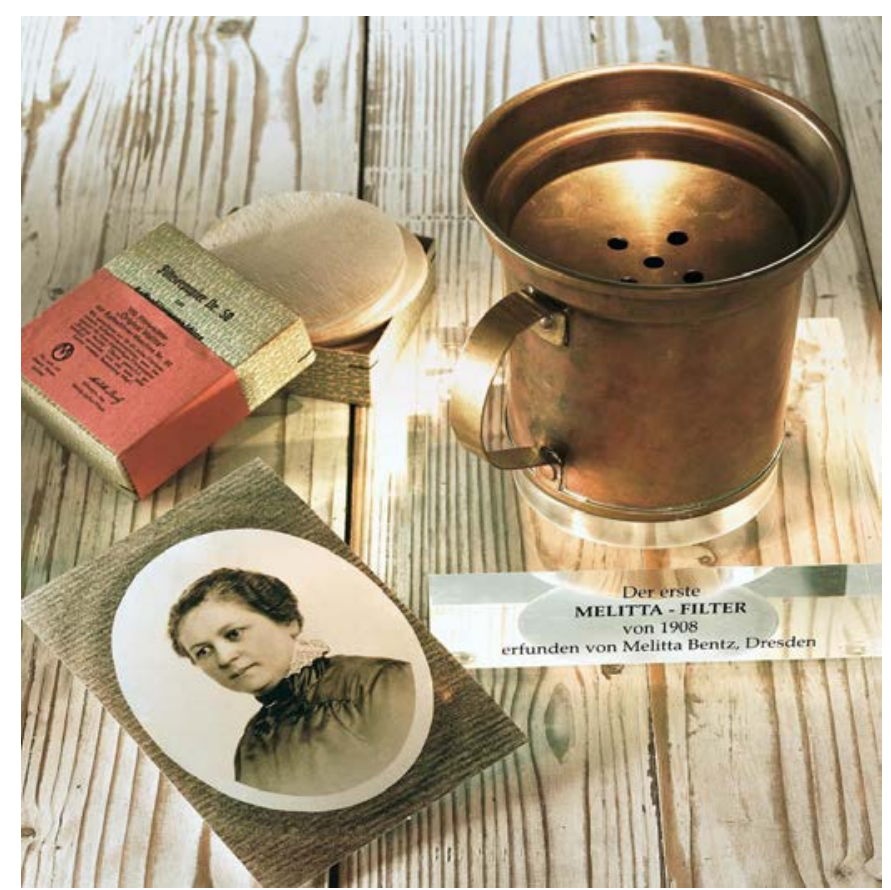

Figura 1: A invenção de Melitta Bentz.

Fonte: BMAS (2014).

\section{MÉTODO DA ANÁLISE COMPARATIVA}

Neste estudo comparativo buscou-se investigar mudanças nos produtos de forma a estabelecer quais características tornavam a versão "eco" mais ambientalmente amigável em relação à versão tradicional. Para isto, como primeira fonte de evidência utilizada foram as informações divulgadas pelas empresas em seus relatórios corporativos e seus websites, já que são estas as informações que o consumidor tem acesso para definir sua escolha.

Posteriormente foram investigados detalhes de processo produtivo que foram atribuídos ao produto devido às suas características. Esta suposição ocorreu devido ao 
fato da empresa não esclarecer completamente as diferenças entre as versões em nenhum de seus canais de comunicação.

\section{RESULTADOS DA ANÁLISE}

A comparação entre os as duas versões do filtro coador de café foi realizada a partir de dois critérios principais (i) o processo de fabricação e (ii) a responsabilidade social, tendo como pano de fundo a investigação da legislação que delimitaria algumas características a serem contempladas pelas duas versões. Cabe salientar ainda que a análise do processo de fabricação foi realizada com foco no produto e na embalagem separadamente, como está descrito a seguir.

\subsection{Processo de fabricação da embalagem}

As informações sobre a embalagem dizem respeito à matéria-prima da embalagem, ou seja, o material para a fabricação do papel, investigado a partir da presença do selo da figura 2. As embalagens das duas versões, eco e convencional, possuem as mesmas características, por isto ambas têm certificação de cadeia de custódia mista, do Conselho de Manejo Florestal (Forestry Stewardship Council - FSC ${ }^{\circledR}$ ) - selo FSC-Misto (Figura 2).

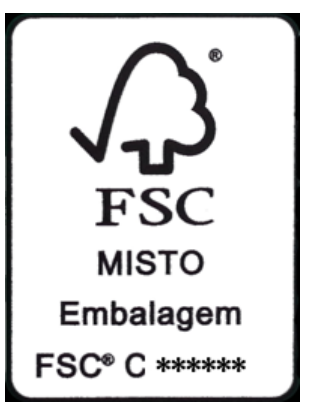

Figura 2: Selo que comprova a certificação da embalagem.

Fonte: FSC (2014).

A documentação referente à certificação, registrada sob o código de licença apresentado no selo ( $\mathrm{FSC}^{\circledR} \mathrm{C}^{* * * * * *}$ ), pode ser acessada no site info.fsc.org. A empresa fabricante das embalagens obteve a certificação em fevereiro de 2011.

A certificação de cadeia de custódia, FSC-CoC (Chain of Custody) garante a rastreabilidade da matéria-prima desde sua produção, sendo aplicada aos produtores que processam a matéria-prima de florestas certificadas. (FSC, 2014).

O selo impresso garante que a embalagem foi fabricada com papel oriundo de madeira controlada, de reflorestamento, que obedece a critérios sociais e econômicos estabelecidos pela $\mathrm{FSC}^{\circledR}$. Este selo certifica o comprometimento com o manejo da matéria prima e a preservação de áreas verdes.

O fabricante das embalagens é certificado segundo as normas FSC-STD-40-003 V1-0 e FSC-STD-40-004 V2-1. A norma FSC-STD040-003 V1-0 foi desenvolvida com o objetivo de facilitar a certificação da cadeia de custódia de empresas de grande porte, que realizam operações semelhantes (mesmas funções, métodos e procedimentos) em parques fabris diversos (FSC, 2007). A empresa fabricante da embalagem, se encaixa nesta descrição, com operações em Ponta Grossa (PR); Valinhos (SP) e Guaíba (RS).

O selo FSC-Misto indica a utilização "Material virgem certificado pela FSC, proveniente de florestas ou plantações certificadas pelo FSC, que não tenha sido 
misturado com material de outra categoria em toda a cadeia de abastecimento" (FSC, 2011, p. 9). Para que um produto possa receber o selo FSC-Misto, a matéria-prima utilizada na sua confecção deve apresentar um dos seguintes requisitos (FSC, 2011, p. 23): (i) proporção declarada de, no mínimo, 70\% de entradas do tipo FSC-Misto; (ii) declaração de crédito FSC-Misto.

\subsection{Processo de fabricação do produto}

O filtro eco possui uma coloração mais escura que os similares convencionais (Figura 3). A aparência marrom clara remete ao papel reciclado, porém a empresa informou que a coloração escura é atribuída à ausência de branqueamento da celulose, que mantém sua cor e textura naturais.

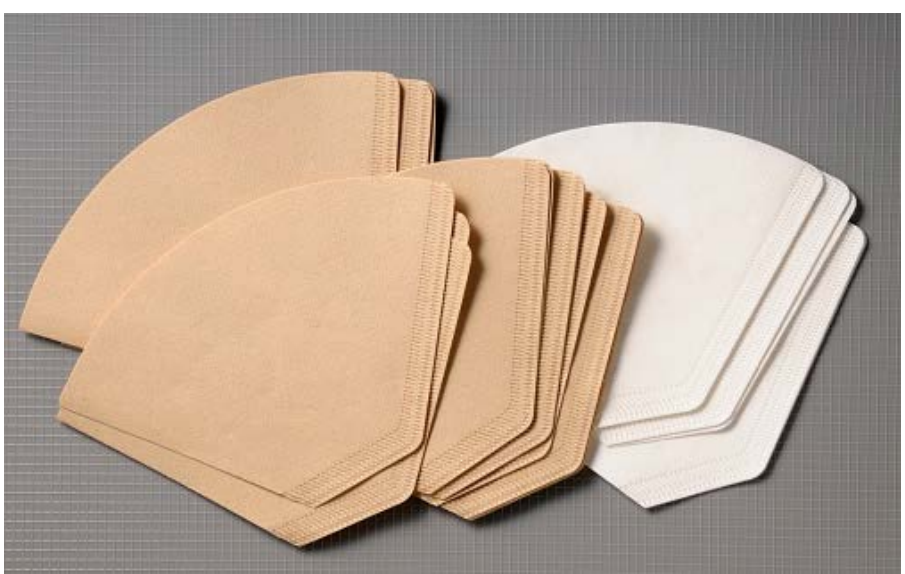

Figura 3: Coadores de papel tradicional (à direita) e eco (à esquerda).

Fonte: RIOU (s.d.).

Conforme Azevedo (2011, p. 12), o branqueamento pode ser definido como um processo que visa branquear a polpa celulósica por meio da remoção e/ou modificação de substâncias químicas capazes de proporcionar cor à polpa. A partir desta informação sobre a cor do produto, foi investigado por meio de outras fontes o processo de branqueamento em si, suas características e consequências ambientais.

O principal elemento que confere cor à polpa celulósica é a lignina. Durante a primeira etapa da produção da polpa, o cozimento, ocorre a degradação da lignina pela ação do licor de cozimento a temperaturas e pressões elevadas. A dissolução da lignina no licor permite a separação das fibras (AZEVEDO, 2011, p. 12). Dependendo do grau de cozimento, a polpa pode conter até $5 \%$ de lignina (GOMES, 2011).

O processo de branqueamento é composto por várias etapas, de acordo com a alvura desejada no produto final. A divisão do processo em etapas também se dá por razões de ordem técnica e econômica (GOMES, 2011). Os compostos responsáveis pela cor da polpa não podem ser removidos simultaneamente em uma única etapa, devido às suas diferentes reatividades e localizações (AZEVEDO, 2011). Segundo Azevedo (2011, p. 14) define-se como alvura a refletância da amostra quando comparada com a refletância de uma superfície padrão, por exemplo, (MgO) utilizando luz com comprimento de onda de $457 \mathrm{~nm}$.

Cada ciclo do processo de branqueamento inclui etapas de oxidação da celulose (geralmente duas, em meio ácido) e uma etapa de extração alcalina para que ocorra a hidrólise (e posterior remoção) da lignina (AZEVEDO, 2011). O Quadro 1 apresenta os estágios de branqueamento com os respectivos reagentes químicos empregados. 
Quadro 1: Estágios do branqueamento da celulose.

\begin{tabular}{|l|l|c|}
\hline ESTÁGIO & REAGENTE QUíMICO & CóDIGO \\
\hline Cloração & Cloro gasoso & $\mathrm{C}$ \\
\hline Extração alcalina & Soda cáustica & $\mathrm{E}$ \\
\hline Hipocloração & Hipoclorito de Sódio ou de Cálcio & $\mathrm{H}$ \\
\hline Dióxido de cloro & Dióxido de cloro & $\mathrm{D}$ \\
\hline Peróxido & Peróxido de hidrogênio & $\mathrm{P}$ \\
\hline Oxigênio & Oxigênio & $\mathrm{O}$ \\
\hline Ozônio & Ozônio & $Z$ \\
\hline Extração oxidadtiva & Soda cáustica e oxigênio & $\mathrm{E}_{\mathrm{O}}$ \\
\hline Extração alcalina com peróxido & Soda cáustica e peróxido de hidrogênio & $\mathrm{E}_{\mathrm{p}}$ \\
\hline
\end{tabular}

Fonte: GOMES (2011).

O Quadro 2 apresenta as sequências mais empregadas, conforme o grau de alvura desejado no produto final (os estágios são representados pelos códigos utilizados no Quadro 1).

Quadro 2: Sequências de branqueamento mais empregadas na indústria.

\begin{tabular}{|l|l|}
\hline GRAU DE ALVURA & SEQUÊNCIA \\
\hline Até 75\% & CEH \\
\hline Entre $75 \%$ e $80 \%$ & CEHH, CED \\
\hline Entre $80 \%$ e $85 \%$ & CHEH, CEHEH, CED, EHD \\
\hline Entre $85 \%$ e $90 \%$ & OC/DEOPD, CEDED, CEHDP, ODEOD \\
\hline Maior que $90 \%$ & CEHEDP, CEDED, CDEDED, OCDEODD \\
\hline
\end{tabular}

Fonte: GOMES (2011).

A preocupação com o impacto ambiental (e consequentes pressões) conduziu, nas últimas décadas, a uma progressiva eliminação do cloro elementar $(\mathrm{Cl} 2)$, principal reagente do processo de branqueamento até então. Desta forma, surgiram as sequências livres de cloro elementar (sequência ECF - Elementar Chlorine Free). A tendência atual é a eliminação total do cloro com as sequências TCF (Total Chlorine Free) (GOMES, 2011). Conforme Voss et al. (1981, apud AZEVEDO, 2011), o cloro elementar potencializa a formação de dioxinas e compostos organoclorados não biodegradáveis. As sequências ECF não eliminam completamente as dioxinas, classificados pela EPA como o mais potente cancerígeno já testado em laboratórios. As dioxinas também estão associadas a doenças dos sistemas endócrino, reprodutor, nervoso e imunológico (FERRAZ, 2009).

A Europa eliminou o uso do cloro, adotando as sequências TCF (FERRAZ, 2009). No Brasil, o Projeto de Lei 4069/2008, que previa proibição ao uso de dióxido de cloro no processo de fabricação de papel, obrigando a adoção de sequências TCF, foi rejeitado em duas comissões da Câmara dos Deputados: Meio Ambiente e Desenvolvimento Sustentável; e Desenvolvimento Econômico, Indústria e Comércio (AGÊNCIA CÂMARA, 2009).

Outra tendência atual é a eliminação total dos efluentes (conceito TEF - Total Effluent Free), ficando a água de lavagem em um circuito fechado (GOMES, 2011). A dificuldade na implantação de um circuito fechado está no aumento da taxa de decomposição de agentes de branqueamento derivados do oxigênio, formação de incrustações, aumento da taxa de corrosão de equipamentos e tubulações [...], além 
de causar prejuízos à qualidade da polpa (COSTA et al., 2006, p. 2). Atualmente, com as sequências ECF, o branqueamento de uma tonelada de polpa consome $60 \mathrm{~m}^{3}$ de água. Com o conceito TEF, é prevista uma redução deste volume para algo entre $20 \mathrm{~m}^{3}$ e 25 $\mathrm{m}^{3}$ (GOMES, 2011).

Desta forma, ao eliminar a etapa de branqueamento da polpa celulósica, o processo de fabricação da versão eco do coador é ambientalmente mais amigável que o da versão convencional, pois deixa de utilizar os diversos reagentes branqueadores que acabariam nos efluentes, assim como o volume de água necessário no processo. Cabe salientar, no entanto, que esta diferença não é esclarecida pela empresa em seus canais de informação, a diferença entre as duas versões em termos detalhados, com informações quantitativas inclusive, não é disponibilizada ao consumidor.

\subsection{Regulamentação de embalagens e produtos alimentícios}

No Brasil, a fabricação de embalagens e equipamentos celulósicos destinados a entrar em contato com alimentos é regulada pela Portaria no 177, de 4 de março de 1999, da Secretaria de Vigilância Sanitária do Ministério da Saúde. Esta Portaria aprova - Regulamento Técnico "Disposições Gerais Para Embalagens e Equipamentos Celulósicos em Contato com Alimentos" e seus Anexos (SVS/MS, 1999, p. 1).

O Anexo I da Portaria 177 apresenta uma lista com as substâncias permitidas para a fabricação de material que entre em contato com alimento. $O$ primeiro item do anexo trata das matérias-primas fibrosas permitidas:

1.1 Fibras celulósicas de primeiro uso, naturais (pasta celulósica química, mecânica, semi-quimica, quimio-termo-mecânica, termomecânica e quimio-mecânica, branqueadas, semi-branqueadas ou não branqueadas) ou artificiais. Admite-se o emprego de antraquinona, desde que não exceda a $30 \mathrm{mg} / \mathrm{kg}$ no produto final (calculado na base seca).

[...]

1.3 Fibras celulósicas provenientes de material reprocessado dentro da produção industrial de embalagens e equipamentos celulósicos destinados a entrar em contato com alimentos.

1.4 Fibras celulósicas provenientes de material reciclado, que cumpram com as exigências descritas no Regulamento Técnico sobre Fibras Celulósicas provenientes de Material Reciclado.

(SMS/SV, 1999, pp. 5-6)

O item 4 do mesmo anexo trata das substâncias especiais para papéis. Neste item, o subitem 4.3.2 trata especificamente de substâncias branqueadoras:

4.3.2 Branqueadores óticos: não devem migrar para o alimento e devem cumprir com o Regulamento Técnico sobre Determinação de Migração de Branqueadores Fluorescentes em Papel, Cartolina e Cartão. No caso de derivados sulfonados de estilbeno: na massa ou na superfície no máximo $0,3 \% \mathrm{~m} / \mathrm{m}$ em relação ao produto final.(SVS/MS, 1999, pp. 16)

O Anexo V da Portaria 177 trata especificamente de papéis de filtro para cocção e filtração a quente. $O$ item 4 deste anexo apresenta os requisitos para estes produtos:

4.1. Os papéis não devem modificar o odor e o sabor dos alimentos.

4.2. O resíduo seco total da extração com água quente não pode ser superior a $10 \mathrm{mg} /$ $\mathrm{dm} 2$ e o conteúdo total de nitrogênio deste extrato (determinado pelo método 
de Kjeldahl) não pode ser superior a $0,1 \mathrm{mg} / \mathrm{dm} 2$.

4.3. No extrato com água quente não deve ser detectado formaldeído ou glioxal, nem os metais: cádmio $(\mathrm{Cd})$, arsênio $(\mathrm{As})$, cromo $(\mathrm{Cr})$, mercúrio $(\mathrm{Hg})$ e chumbo $(\mathrm{Pb})$ em quantidades superiores às estabelecidas no regulamento técnico correspondente a "Contaminantes de Alimentos".

(SVS/MS, 1999, pp. 35)

Desta forma, a Portaria 177 permite a utilização tanto de papéis branqueados quanto não branqueados na fabricação de coadores. As empresas têm a liberdade de escolher o tipo de polpa que utilizarão, respeitando os limites de resíduos especificados para os produtos.

Contudo é importante esclarecer ao público que os papéis destinados a envoltório ou à produção de alimento, como no caso do filtro de café, são materiais virgens sem nenhum conteúdo de material reciclado. A diferença entre eles é apenas a presença ou ausência do processo de branqueamento. Processo este que envolve substâncias químicas nocivas para o meio ambiente, portanto nosso questionamento é o sobre a real necessidade do filtro branco, em contrapondo com o filtro ambientalmente amigável não branqueado.

\subsection{Responsabilidade social}

A responsabilidade social é uma prática voluntária das empresas para a promoção de ações que visam o bem-estar de seu público interno e externo. Sendo uma prática voluntária, o conceito de responsabilidade social não engloba as ações realizadas de forma compulsória, por força de legislação, por exemplo, ou resultantes de incentivos externos (RESPONSABILIDADE SOCIAL, 2014). A evolução do conceito originou variantes que definem "Responsabilidade Social" de formas muitas vezes complementares, distintas ou redundantes (RESPONSABILIDADE SOCIAL, 2014):

- Responsabilidade Social Corporativa (RSC): conceito aplicável geralmente a empresas de grande porte. As ações de RSC focam no ambiente de negócios ou no quadro de funcionários;

- Responsabilidade Social Empresarial (RSE): envolve um público mais amplo de beneficiários que a RSC, focando na qualidade de vida e bem-estar do público interno da empresa. As ações de RSE também objetivam a redução de impactos negativos causados por sua atividade na comunidade e meio ambiente onde atua;

- Responsabilidade Social Ambiental (RSA): o conceito mais amplo de todos, é configurado pelo conjunto de ações que representam não apenas o compromisso de empresas com pessoas e valores humanos, mas também suas preocupações em relação ao meio ambiente (RESPONSABILIDADE SOCIAL, 2014).

A empresa produtora dos filtros de café estudados apresenta, em seu site oficial, o item "Responsabilidade Social" como um dos valores da empresa, com a seguinte descrição: "a empresa e seus colaboradores se empenham na preservação do meio ambiente"; e "a empresa busca apoiar o desenvolvimento das comunidades onde atua".

O mesmo site traz informações sobre o apoio da empresa a projetos sociais. Conforme a própria empresa enuncia: "tem o compromisso com o meio ambiente e a 
qualidade de vida. Essa consciência se manifesta não somente através de produtos ecologicamente corretos, mas também com parcerias efetivas com instituições ambientais de credibilidade e apoio de causas referentes a esses assuntos, o que permite ampliar e aprofundar nosso exercício de responsabilidade socioambiental sustentável.

Os projetos / inciativas listados no site da empresa são os seguintes:

- Instituto ECOAR para a Cidadania: conforme informado na embalagem, "parte da receita com as vendas do coador de papel eco é destinado ao Instituto Ecoar". O Instituto ECOAR para a Cidadania é uma Organização da Sociedade Civil de Interesse Público (OSCIP) criada em 1992, após a Conferência das Nações Unidas para o Meio Ambiente e Desenvolvimento (ECO-92), para "atuar em questões ambientais emergentes, contribuir com a construção de sociedades sustentáveis e influenciar políticas públicas sócio-ambientalmente corretas" (ECOAR, 2014). O ECOAR promove, através de ações de pesquisa e práticas de educação para a sustentabilidade, a divulgação de conhecimentos que "contribuam para a sobrevivência de todas as espécies e sistemas naturais do planeta, para a equidade social e emancipação humana" (ECOAR, 2014).

- Projeto Fazendas Sustentáveis: iniciado em 2008, este é um programa de apoio às fazendas fornecedora do Café Sustentável, utilizado em três linhas do produto café da empresa estudada. Segundo a própria empresa, ela ajuda as escolas rurais, onde estudam os filhos dos trabalhadores destas fazendas, com material escolar e kits de brinquedos educativos que "ensinam de maneira divertida a importância da sustentabilidade" .

- Conselho Brasileiro de Manejo Florestal (Forest Stewardship Council - FSC): tem como missão "difundir e facilitar o bom manejo das florestas brasileiras conforme Princípios e Critérios que conciliam as salvaguardas ecológicas com os benefícios sociais e a viabilidade econômica". Criado em 1993, o FSC é, atualmente o sistema de certificação florestal de maior credibilidade internacional (FSC, 2014).

- Aldeias Infantis S.O.S. (S.O.S. Children's Village): esta é uma Organização Não Governamental (ONG) e sem fins lucrativos criada em 1949, na Áustria, para acolher crianças órfãs, vítimas da II Guerra Mundial. O "Aldeias Infantis" atua na defesa, garantia e promoção dos direitos de crianças, adolescentes e jovens. No Brasil a ONG tem 22 programas em 12 estados e no Distrito Federal. Estes programas são responsáveis pela criação de núcleos familiares com até nove crianças de diferentes idades e sexos, sob os cuidados de uma mãe social (ALDEIAS INFANTIS SOS, 2014).

A partir da colaboração com estas instituições e inciativas entendeu-se que a empresa se enquadra na categoria de Responsabilidade Social Ambiental - RSA e Responsabilidade Social Corporativa - RSC.

\section{CONSIDERAÇÕES FINAIS}

Entre os critérios analisados, o coador eco se destaca em dois (Quadro 3):

- Processo de fabricação. A eliminação da etapa de branqueamento da polpa celulósica reduz consideravelmente o impacto ambiental resultante; 
- Responsabilidade social. Parte da receita obtida com as vendas do coador eco era destinada ao Instituto Ecoar.

Quadro 3: Critérios analisados.

\begin{tabular}{|l|l|l|l|}
\hline & $\begin{array}{l}\text { FABRICAÇÃO: } \\
\text { EMBALAGEM }\end{array}$ & $\begin{array}{l}\text { FABRICAÇÃO: } \\
\text { PRODUTO }\end{array}$ & $\begin{array}{l}\text { RESPONSABILIDADE } \\
\text { SOCIAL }\end{array}$ \\
\hline Versão eco & Certificação FSC ${ }^{\circledR}$ & Polpa não branqueada & $\begin{array}{l}\text { Apoio a projetos sociais e } \\
\text { Doação p/ Instituto ECOAR }\end{array}$ \\
\hline $\begin{array}{l}\text { Versão } \\
\text { convencional }\end{array}$ & Certificação FSC ${ }^{\circledR}$ & Polpa branqueada & Apoio a projetos sociais \\
\hline
\end{tabular}

Fonte: Elaborado pelos autores, com base na pesquisa realizada.

Pressupõem-se que o produto Eco é o resultado de uma opção voluntária da empresa, pois o presente trabalho não analisou outras possíveis motivações da empresa para esta escolha, como demanda do mercado, fixação de uma imagem institucional, etc. Desta forma, de acordo com os critérios analisados, o filtro eco é, de fato, ambientalmente melhor que o filtro convencional.

No entanto, as vantagens deste produto não foram exploradas em nenhum canal de comunicação da empresa. Como instituição, a empresa busca demonstrar preocupação com o ambiente onde atua, patrocinando e participando de ações que visam o bem-estar de seu público interno e externo como todas as grandes empresas deste e de outros setores, como uma exigência de boa imagem perante seus clientes. O selo de certificação da matéria prima da embalagem ajuda a reforçar esta imagem.

Contudo questionamos neste trabalho o papel educador ou multiplicador de conhecimento que as empresas devem assumir no cenário atual, ou mesmo a exigência da sociedade perante os produtos que consome. Quando uma empresa oferta uma versão eco, esta deve ser encarada não como um teste de mercado, mas sim como uma responsabilidade de verdadeiramente levar um benefício ambiental. Deve contemplar o envolvimento e o interesse para que o produto dê certo e que os consumidores realmente identifiquem a melhoria proposta. A pergunta seria: porque ainda fazemos o produto convencional? E não: será que o público vai aceitar a versão eco? Para isto é fundamental divulgar suas diferenças e ressaltar os benefícios de uma em relação à outra.

\section{REFERÊNCIAS}

ABIC. Indicadores da indústria de café no Brasil - 2015. 2016. Disponível em: <http:// http://www.abic.com.br/publique/cgi/cgilua.exe/sys/start.htm?sid=61\#5103>. Acesso em: 25 maio 2016.

AGÊNCIA CÂMARA. Comissão mantém uso de dióxido de cloro na fabricação de papel. 2009. Disponível em: $<$ http://www2.camara.leg.br/camaranoticias/noticias/INDUSTRIA-ECOMERCIO/138801-COMISSAO-MANTEM-USO-DE-DIOXIDO-DE-CLORO-NAFABRICACAO-DE-PAPEL.html>. Acesso em: 19 jul. 2014.

ALDEIAS INFANTIS SOS. 2014. Disponível em <http://www.aldeiasinfantis.org.br/>. Acesso em 7 jul. 2014.

AZEVEDO, M. A. B. Diferentes processos de branqueamento da celulose e seus efeitos nas propriedades físicas e cristalinidade. 2011. Tese de Doutorado - Universidade 
Federal de Minas Gerais, Belo Horizonte, 2011. Disponível em:

<http://hdl.handle.net/1843/SFSA-95JVPB>. Acesso em: 7 jul. 2014.

BMAS. Bundesministerium für Arbeit und Soziales - Soziale Situation der Frau. 2014. Disponível em <https://www.in-die-zukunft-gedacht.de/de/page/84/themenabschnitt/779/dokument/734/themen.html>. Acesso em 20 jun. 2014.

COSTA, M. M. et al. Nova tecnologia de branqueamento de celulose adaptada ao fechamento do circuito de água. Rev. Árvore, v. 30, n. 1, p. 129-139, 2006. Disponível em: <http://www.scielo.br/pdf/rarv/v30n1/28517.pdf>. Acesso em: 17 jul. 2014.

ECOAR. 2014. Disponível em: <http://www.ecoar.org.br>. Acesso em: 4 jul. 2014.

FERRAZ, J. M. G. O Papel Nosso de Cada Dia. 2009. Disponível em:

<www.cnpma.embrapa.br/down_hp/408.pdf>. Acesso em: 17 jul. 2014.

FERREIRA, C. Otimista, Melitta prevê receita de $\mathrm{R} \$ 1$ bi no país em dois anos. Valor Econômico, São Paulo, 20 ago. 2013. Disponível em:

<http://www.valor.com.br/agro/3238856/otimista-melitta-preve-receita-de-r-1-bi-nopais-em-dois-anos>. Acesso em: 21 jul. 2014.

FSC. FSC Standard for Multi-site Certification of Chain of Custody Operations. 2007. Disponível em: <http://www.rainforest-alliance.org/forestry/documents/multi.pdf>. Acesso em: 6 jul. 2014.

FSC. FSC Standard for Chain of Custody Certification. 2011. Disponível em:

$<$ http://br.fsc.org/download.fsc-std-40-004v2-

1enchainofcustodycertification.125.pdf>. Acesso em: 6 jul. 2014.

FSC. FSC Forest Stewardship Council Brasil (FSC-BR) - Cadeia de Custódia (CoC.) 2014. Disponível em: <http://br.fsc.org/cadeia-de-custdia-coc.259.htm>. Acesso em: 4 jul. 2014.

GOMES, F. M. Branqueamento da Celulose. Lorena: 2011. Disponível em: <http://br.fsc.org/cadeia-de-custdia-coc.259.htm>. Acesso em: 4 jul. 2014.

ORGANICS BRASIL. Brazilian Organic Trends And News Biofrach 2016. Disponível em: $<$ http://www.organicsbrasil.org/dnfile/cjo1gb6icqbjt1g73sht/pdf/downloads_relatorio s/1/cjo1gb6icqbjt1g73shtpdf.pdf>. Acesso em 8 jun. 2016.

RESPONSABILIDADE SOCIAL. O que é Responsabilidade Social? 2014. Disponível em: $<$ http://www.responsabilidadesocial.com/o-que-e-responsabilidade-social/>. Acesso em: 6 jul. 2014.

RIOU. Filter coffee. [s.d.]. Disponível em:

<http://www.gettyimages.com/license/556589387>. Acesso em: 9 jun. 2016.

SANTOS, R. M.; LIMA, D. R. Coffee: The Revolutionary Drink for Pleasure and Health. [S.I.]: Xlibris Corporation, 2007.

STANLEY, A. Mothers and Daughters of Invention: Notes for a Revised History of Technology. [S.I.]: Rutgers University Press, 1995.

SVS/MS - Ministério da Saúde / Secretaria de Vigilância Sanitária. Portaria no 177, de 04 de março de 1999. Disponível em: <http://e-

legis.anvisa.gov.br/leisref/public/showAct.php?id=53>. Acesso em 10 jul. 2014. 